\title{
Protein Kinase A-Induced Phosphorylation of the p65 Subunit of Nuclear Factor- $\kappa$ B Promotes Schwann Cell Differentiation into a Myelinating Phenotype
}

\author{
Choya Yoon, ${ }^{1,3}$ Zeljka Korade, ${ }^{1,2}$ and Bruce D. Carter ${ }^{1,2,3}$ \\ ${ }^{1}$ Department of Biochemistry, ${ }^{2}$ Vanderbilt Kennedy Center, and ${ }^{3}$ Center for Molecular Neuroscience, Vanderbilt University Medical School, Nashville, \\ Tennessee 37232
}

\begin{abstract}
Axon-Schwann cell interactions are critical for myelin formation during peripheral nerve development and regeneration. Axonal contact promotes Schwann cell precursors to differentiate into a myelinating phenotype, and cAMP-elevating agents can mimic this; however, the mechanisms underlying this differentiation are poorly understood. We demonstrated previously that the transcription factor nuclear factor $-\kappa \mathrm{B}(\mathrm{NF}-\kappa \mathrm{B})$ is required for myelin formation by Schwann cells (Nickols et al., 2003), although how it is activated during this process remained to be determined. Here, we report that culturing Schwann cells with sensory neurons results in the activation of cAMPdependent protein kinase (PKA), and this kinase phosphorylates the p65 subunit of NF- $\kappa$ B at S276. The phosphorylation was also induced in cultured Schwann cells by treatment with forskolin, dibutyryl-cAMP, or by overexpression of a catalytic subunit of PKA, and this increased the transcriptional activity of NF- $\kappa$ B. In developing perinatal rat sciatic nerve, the kinetics of p65 phosphorylation at $\$ 276$ paralleled that of PKA and NF- $\kappa$ B activation. To elucidate the role of p65 phosphorylation in myelin formation, we overexpressed an S276A mutant of p65 in cultured Schwann cells, which blocked PKA-mediated transcriptional activation of NF- $\kappa$ B. When the Schwann cells expressing the mutant were cocultured with sensory neurons, there was a $45 \%$ reduction in the number of myelinated fibers relative to controls, demonstrating a requirement for p65 phosphorylation by PKA during myelin formation.
\end{abstract}

Key words: glia; Schwann; myelin; cAMP; nuclear factor- $\kappa \mathrm{B}$; Oct-6

\section{Introduction}

During development, Schwann cell precursors, originally derived from the neural crest, migrate out of the dorsal root ganglia along axons of sensory and motor neurons. In response to axonal signals, the precursors arrest, elongate, and begin to wrap selected axons, eventually forming myelin. The molecular cues regulating this complex choreography are essentially unknown; however, one signal that can mimic axonal contact with Schwann cells is cAMP. Originally recognized for its ability to upregulate the myelin marker galactocerebroside in Schwann cells (Sobue and Pleasure, 1984), cAMP was subsequently shown to increase the expression of a number of myelin genes such as myelin protein zero (P0) (Lemke and Chao, 1988; Morgan et al., 1991) and the transcription factor SCIP/Oct-6/Tst-1, which is an essential regulator of Schwann cell differentiation into a myelinating phenotype (Monuki et al., 1989; Bermingham et al., 1996; Jaegle et al., 1996).

The best known downstream effector of cAMP is protein kinase $\mathrm{A}$ (PKA), which is activated on the nucleotide binding to the regulatory subunit of the kinase. Inhibition of PKA was shown to

Received Sept. 27, 2007; revised Feb. 29, 2008; accepted March 1, 2008.

This work was supported by National Institutes of Health Grant NSO4248 (B.D.C.). We thank Hannah Edelman for technical assistance and members of the Carter laboratory for helpful comments and discussion.

Correspondence should be addressed to Bruce D. Carter, Department of Biochemistry, 655 Light Hall, Vanderbilt University School of Medicine, Nashville, TN 37232. E-mail: bruce.carter@vanderbilt.edu.

DOI:10.1523/JNEUROSCI.4439-07.2008

Copyright $\odot 2008$ Society for Neuroscience $\quad$ 0270-6474/08/283738-09\$15.00/0 block the morphological changes in Schwann cells induced by raising cAMP levels with forskolin and prevented the formation of myelin in Schwann cell-dorsal root ganglia (DRG) neuron cocultures (Howe and McCarthy, 2000). However, the critical targets of PKA in promoting Schwann cell differentiation into the myelinating phenotype have yet to be identified.

Recently, we demonstrated that the transcription factor nuclear factor- $\kappa \mathrm{B}(\mathrm{NF}-\kappa \mathrm{B})$ is an essential promoter of myelin formation (Nickols et al., 2003). This transcription factor exists in mammals as homodimers or heterodimers of five different subunits (relA, also called p65, relB, c-rel, p50, and p52). Inhibition of NF- $\kappa \mathrm{B}$ or deletion of the p65 gene blocked the formation of myelin in Schwann cell-DRG neuron cocultures (Nickols et al., 2003). In unstimulated cells, NF- $\kappa \mathrm{B}$ is sequestered in the cytoplasm through the interaction with an inhibitory protein, nuclear factor $\kappa \mathrm{B}$ inhibitor $(\mathrm{I} \kappa \mathrm{B})$, which is phosphorylated and degraded after a variety extracellular stimuli such as cytokines, growth factors, and bacterial/viral infection (Sun and Andersson, 2002; Hoffmann et al., 2006; Perkins and Gilmore, 2006). Release from $\mathrm{I} \kappa \mathrm{B}$ unmasks the nuclear localization signal of $\mathrm{NF}-\kappa \mathrm{B}$, which directs it to the nucleus in which NF- $\kappa \mathrm{B}$-dependent gene transcription occurs. In addition, there is increasing evidence that posttranslational modifications, such as phosphorylation, acetylation, and ubiquitination, of the $\mathrm{p} 65$ subunit of NF- $\kappa \mathrm{B}$ can also control NF- $\kappa \mathrm{B}$-dependent transcription (Campbell and Perkins, 2004a,b). Of particular note, serine 276 was shown to be phos- 
phorylated by PKA, which increased the interaction of p65 with transcription coactivators CREB (cAMP response elementbinding protein) binding protein (CBP) and P300, leading to enhanced transcriptional activity of NF- $\kappa \mathrm{B}$ (Zhong et al., 1997, 1998).

In this report, we demonstrate that PKA activation in Schwann cells leads to phosphorylation of p65 at serine 276, and this increases its transcriptional activity. This phosphorylation of $\mathrm{NF}-\kappa \mathrm{B}$ was observed in both myelinating cocultures and developing sciatic nerves. Mutating S276 to alanine attenuated NF- $\kappa \mathrm{B}-$ dependent transcription and inhibited Schwann cell differentiation into a myelinating phenotype in response to elevated cAMP or after coculture with sensory neurons. These results suggest that PKA-mediated phosphorylation and activation of NF- $\kappa \mathrm{B}$ is required for the formation of peripheral myelin.

\section{Materials and Methods}

Primary Schwann cell cultures. Primary rat Schwann cells were isolated from sciatic nerves of 4- to 5-d-old Sprague Dawley rats. For purification, the cells were treated with cytosine arabinoside $(10 \mu \mathrm{M})$ twice for $24 \mathrm{~h}$ and subjected to immunopanning with an antibody against the extracellular domain of p75 (kindly provided by M. Chao, New York University, New York, NY) (Huber and Chao, 1995). The cells were expanded on collagen (type I from rat tail; Sigma, St. Louis, MO)-coated plates in DMEM supplemented with 10\% FBS (Sigma) and forskolin ( $2 \mu \mathrm{M}$; Sigma). For immunoprecipitation experiments, the confluent cells were cultured in DMEM plus $10 \%$ FBS for $3 \mathrm{~d}$ then in serum-free, defined media, which consisted of a 1:1 mixture of DMEM and Ham's F-12 with N2 supplement (Invitrogen, Carlsbad, CA), for another $2 \mathrm{~d}$ before treatment with forskolin $(20 \mu \mathrm{M})$, dibutyryl-cAMP (db-cAMP) (500 $\mu \mathrm{M}$; BIOMOL Research Laboratories, Plymouth Meeting, PA), and/or H89 (10 $\mu \mathrm{M}$; Sigma).

DRG-Schwann cell cocultures. Myelinating Schwann cell-DRG neuron cocultures were established using DRG isolated from E15 rats or E13.5 mice as described with modifications (Nickols et al., 2003). The neurons and Schwann cells from the DRG were cocultured in Ultraculture media (Lonza Walkersville, Walkersville, MD) supplemented with 10\% FBS (HyClone Laboratories, Logan, UT), 2 mM L-glutamine (Invitrogen), and $50 \mathrm{ng} / \mathrm{ml} \mathrm{NGF}$ (Harlan, Indianapolis, IN) at a density of 70,000 cells/2.2 $\mathrm{cm}^{2}$ collagen-coated coverslip. Myelination was induced $5 \mathrm{~d}$ later by adding $50 \mu \mathrm{g} / \mathrm{ml}$ ascorbic acid, and the cultures were maintained by refeeding every $2 \mathrm{~d}$ with fresh media containing ascorbic acid. For cultures of pure rat DRG neurons, to be seeded with Schwann cells, the DRG were dissociated and plated at a density of 30,000 cells $/ 2.2 \mathrm{~cm}^{2}$ coverslip in serum-free Ultraculture media with $2 \mathrm{~mm} \mathrm{~L}$-glutamine and $50 \mathrm{ng} / \mathrm{ml}$ NGF (Harlan). The cells were then treated twice for $48 \mathrm{~h}$ with uridine (10 $\mu \mathrm{M})$ and fluorodeoxyuridine $(10 \mu \mathrm{M})$ to remove all non-neuronal cells. For seeding rat Schwann cells onto the neurons, the Schwann cells were electroporated $(300,000$ cells per cuvette) using the nucleofector mouse embryo fibroblast mixture 1 (program T20; Amaxa Biosystems, Gaithersburg, MD) and then plated onto the neurons (300,000 cells per coverslip). This method resulted in a minimum of $50 \%$ of the cells transfected, based on expression of green fluorescent protein (GFP) from pmax-GFP (Amaxa Biosystems). After allowing Schwann cells to populate the neurons for $2 \mathrm{~d}$, myelination was initiated by changing to ascorbic acid-containing media. For some experiments, the PKA inhibitor H89 (10 $\mu \mathrm{M}$; Sigma) or KT5720 (10 $\mu \mathrm{M}$; BIOMOL Research Laboratories) were added $2 \mathrm{~d}$ after adding ascorbic acid. All animal protocols were approved by the Animal Care and Use Committee at Vanderbilt University.

NF- $\kappa B$ reporter mice. A line of transgenic mice expressing Photinus luciferase cDNA under the control of an NF- $\kappa \mathrm{B}$-dependent promoter (Blackwell et al., 2000) was crossed with wild-type CD1 mice, and the DRG were collected on gestation day 13.5. DRG-Schwann cell cocultures from heterozygous mice were maintained as described above and harvested $2 \mathrm{~d}$ after initiating myelination and the level of endogenous luciferase activity was measured according to the instructions of the manu- facturer (Promega, Madison, WI). The light units were normalized to protein concentration.

Plasmids. Expression vectors encoding wild-type p65 and the S276A mutant as well as the catalytic subunit of PKA were generous gifts from D. Ballard (Vanderbilt University, Nashville, TN), A. Ghosh (Yale University, New Haven, CT), and R. O'Brien (Vanderbilt University), respectively. For the S276D mutant, site-directed mutation of p65 was generated using PCR mutagenesis technique. The sequence of PCR primer used was CAGCTGCGGCGGCCTTCCGACCGGGAGCTC (the site of mutation is underlined). The NF- $\kappa \mathrm{B}-$ luciferase construct was kindly provided by M. Chao (New York University, New York, NY), and the mutant I $\kappa \mathrm{B}(\mathrm{I} \kappa \mathrm{Bm})$ plasmid was described previously [a gift from Dr. L. Kerr, Vanderbilt University (Chen et al., 1999)].

Total RNA isolation, first-strand cDNA synthesis, primer validation, and quantitative PCR. Total RNA was isolated from the cells using Trizol (Invitrogen). Purification of total RNA was done using RNeasy Mini kit (Qiagen, Valencia, CA) and included on-column digestion of DNA during the RNA purification step using RNase-Free DNase Set (Qiagen). Total RNA (100 ng) from each sample was reverse transcribed to cDNA using a High Capacity cDNA Archive kit (Applied Biosystems, Foster, City, CA). Real-time PCR was performed with an ABI Prism 7300 System (Applied Biosystems, Foster, City, CA) using $1 \mathrm{ng}$ of cDNA per $50 \mu \mathrm{l}$ of reaction volume, $2 \times$ SYBR green master mix, and gene-specific primers. All samples were run in triplicate. Data from the PCR reactions were analyzed using the comparative cycle number determined as threshold (Ct) method (Kurrasch et al., 2004). Differential expression was calculated as $\Delta \Delta \mathrm{Ct}$ against expression of phosphoglycerate kinase 1 (Pgk1) as normalizer. We designed primers $(\sim 20 \mathrm{bp})$ to yield $85-110$ bp PCR amplicons using Primer3 software (http://frodo.wi.mit.edu/) for Oct-6 and Pgk1: Oct- 6 forward, TCCСТTTCTCTTCСССТCTC; Oct-6 reverse, GGCTCTGGTAAAACGAAACG; Pgk1 forward, GGCTCGAGCTAAGCAGATTG; Pgk1 reverse, GCTTTCACCACCTCATCCAT. These two validated primer sets show a slope between -3.10 and -3.58 with $R^{2}>0.99$.

Immunoprecipitation and immunoblotting. Primary Schwann cells, DRG-Schwann cell cocultures, and homogenates of sciatic nerves were lysed in $500 \mu \mathrm{l}$ of NP-40 lysis buffer [50 mM Tris- $\mathrm{HCl}$ pH 8.0, $150 \mathrm{~mm}$ $\mathrm{NaCl}, 1 \% \mathrm{NP}-40$, PMSF $(100 \mu \mathrm{g} / \mathrm{ml})$, aprotinin $(1 \mu \mathrm{g} / \mathrm{ml})$, leupeptin (1 $\mu \mathrm{g} / \mathrm{ml})$, and pepstatin $(1 \mu \mathrm{g} / \mathrm{ml})]$. The supernatants were collected by centrifugation at $12,000 \mathrm{rpm}$ for $10 \mathrm{~min}$ at $4^{\circ} \mathrm{C}$, and the protein concentration was determined by Bradford assay (Bio-Rad, Hercules, CA). For immunoprecipitation, $0.5-0.8 \mathrm{mg}$ of protein diluted in lysis buffer was incubated with a polyclonal p65 antibody (catalog \#100-4165; Rockland Immunochemicals, Gilbertsville, PA) at $4^{\circ} \mathrm{C}$ overnight. Immunoprecipitates were subjected to SDS-PAGE and Western blotting with an antibody to p65 (1:2000; Rockland Immunochemicals) or p65 phosphorylated at serine 276 (catalog \#3037S; 1:1000; Cell Signaling Technology, Beverly, MA). To detect Oct-6/SCIP, an antibody against Oct-6 (1:600; generously provided by Dr. D. Meijer, Erasmus University Medical Center, Rotterdam, The Netherlands) was used.

In vitro protein kinase $A$ assay. The determination of PKA activity in cultured Schwann cells, dissociated DRG-Schwann cell cultures, and sciatic nerves was performed using the SignaTect cAMP-dependent Protein Kinase A assay system according to the instructions of the manufacturer (Promega). For sciatic nerves, the tissue was first dissociated by Dounce homogenization in the lysis buffer supplied by the manufacturer.

Electrophoretic mobility shift assay. The DNA binding of NF- $\kappa \mathrm{B}$ was determined by a gel-shift assay with ${ }^{32} \mathrm{P}$-labeled, double-stranded NF- $\kappa \mathrm{B}$ consensus oligonucleotide (Promega) as described previously (Gentry et al., 2000). For super-shift analysis, antibodies against p65 (relA) (catalog \#100-4165, Rockland Immunochemicals; and catalog \#SC-109, Santa Cruz Biotechnology, Santa Cruz, CA) were used.

Myelin basic protein immunostaining in DRG-Schwann cell cocultures. To quantify myelin formation, the cocultures were fixed after 9-10 d with ascorbic acid using 3.7\% (w/v) formaldehyde for $15 \mathrm{~min}$ at room temperature, blocked with 5\% BSA and 5\% normal goat serum in $1 \%$ Triton X-100/PBS for $1 \mathrm{~h}$, followed by avidin/biotin block (Vector Laboratories, Burlingame, CA). After overnight incubation with myelin ba- 
sic protein (MBP) antibody (1:500; Sternberger Monoclonals, Lutherville, MD), biotinylated anti-mouse (1:1000; Vector Laboratories) and streptavidin-conjugated cyanine 3 (Jackson ImmunoResearch, West Grove, PA) were used to visualize MBP. For quantification, the total number of MBP-positive myelin segments on each coverslip was determined and then averaged and normalized relative to the number for those transfected with control vector.

Luciferase NF- $\kappa B$ reporter assay. Primary Schwann cells were transfected using Effectene (Qiagen) following the instructions of the manufacturer. The transfection efficiency using this method was $\sim 50 \%$, based on the expression of GFP. For the reporter assay, $24 \mathrm{~h}$ after transfection, the cells were treated with dibutyryl-cAMP $(500 \mu \mathrm{M})$ or forskolin $(20$ $\mu \mathrm{M})$ with or without $\mathrm{H} 89(10 \mu \mathrm{M})$ for $8 \mathrm{~h}$ and harvested in $1 \times$ passive lysis buffer, and luciferase activity was measured according to the instructions of the manufacturer (Dual Luciferase Assay kit; Promega) using a luminometer (OPTOCOMP 1 Version 1.10; CMGM Instruments, Hamden, CT). All luciferase activities were normalized for transfection efficiency using the activity of a Rous sarcoma virus-Renilla construct (Promega).

\section{Results}

\section{Elevation of cAMP induces phosphorylation of the p65} subunit of NF- $\kappa$ B at S276 in cultured Schwann cells

Stimulation of Schwann cells with cAMP analogs or cAMP elevating agents, such as forskolin, is known to induce their differentiation into a myelinating phenotype (Sobue and Pleasure, 1984; Sobue et al., 1986; Shuman et al., 1988; Monuki et al., 1989; Zorick et al., 1996). Because we demonstrated previously that activation of the transcription factor NF- $\kappa \mathrm{B}$ in Schwann cells is necessary for them to myelinate sensory neurons in culture (Nickols et al., 2003) and Zhong et al. demonstrated that cAMPdependent kinase (PKA) phosphorylation of the p65 subunit of $\mathrm{NF}-\kappa \mathrm{B}$ at serine 276 increased its transcriptional activity (Zhong et al., 1997, 1998), we hypothesized that increasing cAMP in Schwann cells would increase the activity of NF- $\kappa \mathrm{B}$. To test this hypothesis, rat Schwann cells, cultured in defined media without serum, were treated with the cell-permeable cAMP analog dbcAMP or forskolin, and the phosphorylation of p65 was measured using an antibody specific for $\mathrm{p} 65$ phosphorylated at serine 276. Both db-cAMP and forskolin induced phosphorylation of p65 within $1 \mathrm{~h}$ of treatment (Fig. 1) and also activated PKA (data not shown). To further demonstrate that activated PKA was able to induce phosphorylation of p65, we overexpressed the catalytic subunit of PKA in Schwann cells and found that this was sufficient for S276 phosphorylation (Fig. 1). Together, these results indicate that increasing cAMP or activation of PKA in Schwann cells results in the phosphorylation of the p65 subunit of NF- $\kappa \mathrm{B}$.

\section{Phosphorylation of p65 increases NF- $\kappa$ B transcriptional activity but not its DNA binding}

To determine whether PKA-induced phosphorylation of p65 affects NF- $\kappa \mathrm{B}$-dependent gene transcription, we performed reporter assays in cultured Schwann cells. Both db-cAMP and forskolin stimulated reporter gene expression by 3- to 3.5-fold, and the response was completely blocked by H89, suggesting the involvement of PKA (Fig. $2 A$ ). The activation of the reporter by forskolin was specific for NF- $\kappa \mathrm{B}$ as indicated by the ability of $\mathrm{I} \kappa \mathrm{Bm}$, which acts as a super-repressor of NF- $\kappa \mathrm{B}$ signaling, to block the effect. Overexpression of the $\mathrm{p} 65$ subunit also potently increased NF- $\kappa \mathrm{B}$-dependent transcription, and this activity was further enhanced by the addition of db-cAMP or forskolin. This increase was, again, inhibited by $\mathrm{H} 89$, suggesting a role for PKA in enhancing NF- $\kappa \mathrm{B}$-dependent transcription. Similar to inhibiting PKA, expression of a mutant p65 with serine 276 changed to alanine (S276A) prevented any significant increase in NF- $\kappa \mathrm{B}$ ac-

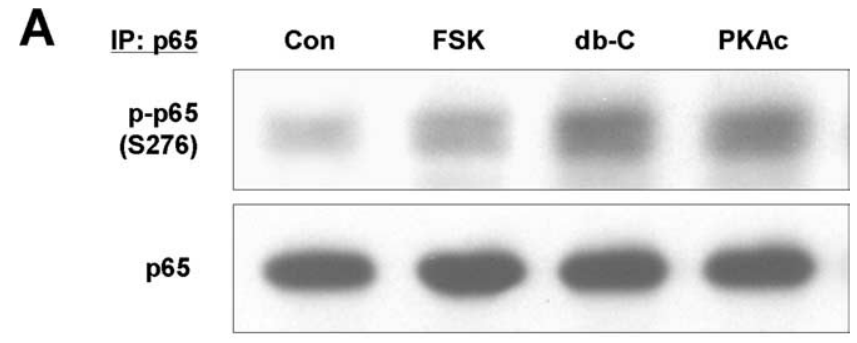

B

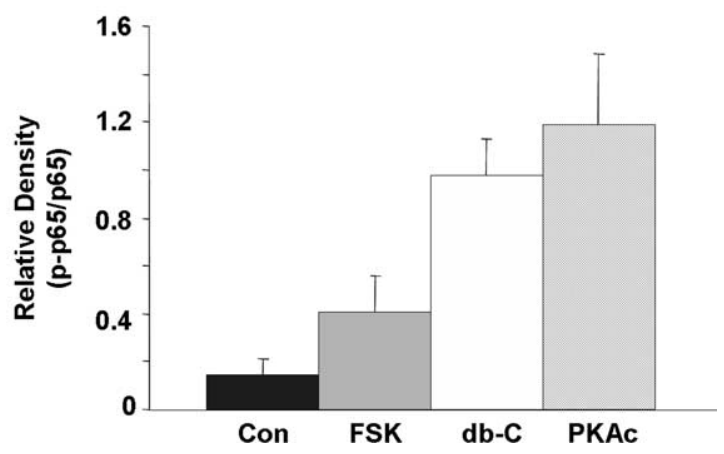

Figure 1. Phosphorylation of the NF- $\kappa$ B subunit $p 65$ is induced by the elevation of $C A M P$ in cultured Schwann cells. A, Schwann cells were transfected with the control vector or PKAcexpressing plasmid. The control cells were left untreated or treated with forskolin $(20 \mu \mathrm{M})$ or db-CAMP $(500 \mu \mathrm{M})$ for $1 \mathrm{~h}$. The cells were lysed and p65 immunoprecipitated (IP) followed by Western blot analysis for phospho-S276 p65 and total p65. The image is a representative of three experiments. B, Quantitative analysis of the amount of phospho-p65 normalized to the total amount of $p 65$. Data represent mean \pm SEM from three trials.

tivity in response to $\mathrm{db}$-cAMP and forskolin. This result not only suggested that serine 276 on p65 was critical for the enhanced transcription activity after elevation of cAMP, but it also indicated that expression of the mutant $\mathrm{p} 65$ prevents PKA-mediated activation of the endogenous, wild-type p65 (Fig. $2 \mathrm{~A}$ ).

To confirm that PKA is able to modulate NF- $\kappa \mathrm{B}$ activity, we also transfected Schwann cells with the catalytic subunit of PKA (PKAc) and found that NF- $\kappa \mathrm{B}$-dependent transcription was upregulated (Fig. 2A). Stimulation with forskolin and db-cAMP synergistically augmented the expression of luciferase and H89 ablated the response, indicating that cAMP-driven PKA activation enhances the transcriptional activity of NF- $\kappa$ B in Schwann cells. These effects were specific for NF- $\kappa \mathrm{B}$ because mutation of the NF- $\kappa \mathrm{B}$ binding site in the reporter prevented activation by PKAc, forskolin, and db-cAMP (data not shown).

Typically, the activation of NF- $\kappa \mathrm{B}$ transcription is accompanied by increased DNA binding. However, when we treated the Schwann cells with forskolin or db-cAMP, there was no detectable change in NF- $\kappa$ B binding by gel-shift assay (Fig. 2 B). Similarly, transfection of the cells with PKAc, which increased p65 phosphorylation (Fig. 1) and NF- $\kappa$ B transcriptional activity (Fig. $2 A$ ), only modestly increased its binding to DNA (Fig. $2 B$ ). These results suggest that, in Schwann cells, PKA activates transcription by NF- $\kappa \mathrm{B}$ already bound to regulatory elements in the genome.

\section{p65 phosphorylation is necessary for cAMP-mediated Schwann cell differentiation}

Because cAMP is known to induce the differentiation of Schwann cells into a myelinating phenotype, we hypothesized that this may occur through an NF- $\kappa \mathrm{B}$-dependent mechanism involving PKA- 


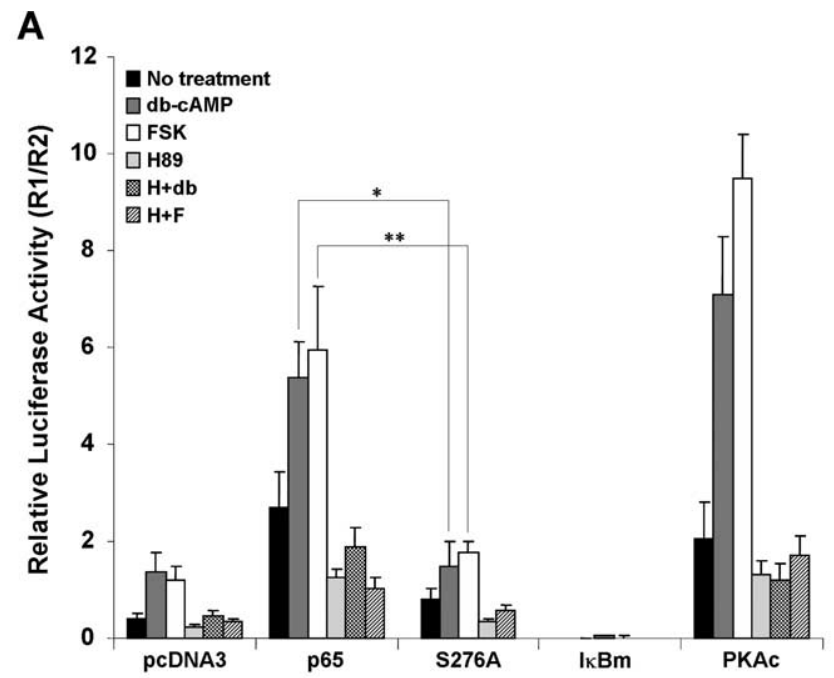

B

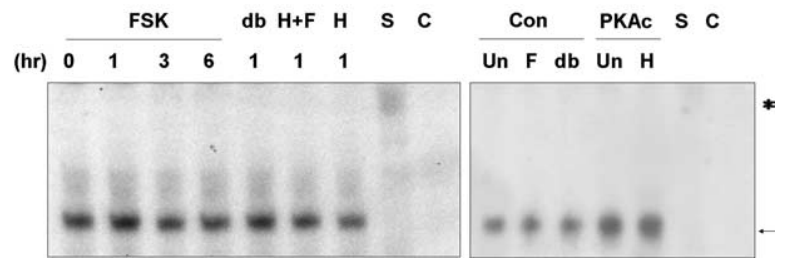

Figure 2. Phosphorylation of $p 65$ at serine 276 increases the transcriptional activity of NF- $\kappa B$ but not its DNA binding. $A$, Schwann cells were transfected with control vector or expres-

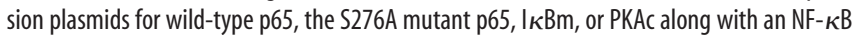
luciferase reporter and Renilla for normalization. Twenty-four hours later, the cells were treated with db-CAMP $(500 \mu \mathrm{M})$, forskolin $(20 \mu \mathrm{M} ; \mathrm{FSK}), \mathrm{H} 89(10 \mu \mathrm{M})$, or a combination of H89 and $\mathrm{db}$-CAMP $(\mathrm{H}+\mathrm{db})$ or H89 and FSK $(\mathrm{H}+\mathrm{F})$ for $8 \mathrm{~h}$ and then harvested, and luciferase activity was measured. The mean \pm SEM of the luciferase activity (RLU1) relative to Renilla (RLU2) is depicted. ( $n=3 ;{ }^{*} p=0.018$; ${ }^{* *} p=0.002$, based on a Student's $t$ test). $\boldsymbol{B}$, Electrophoretic mobility shift assay (EMSA) analysis of lysates from Schwann cells treated with forskolin for various times, as indicated, or for $1 \mathrm{~h}$ with FSK, db-CAMP (db), H89 (H), or forskolin + H89 $(\mathrm{H}+\mathrm{F})$. In the right, the cells were transfected with control vector or one expressing PKAc. The band corresponding to NF- $\kappa B$ binding (arrowhead) was confirmed by super shift using an antibody to p65 (S) ( ${ }^{*}$ indicates the shifted band) and by adding excess unlabeled oligonucleotide (C).

mediated phosphorylation of p65. Therefore, Schwann cells were treated for $24 \mathrm{~h}$ with $\mathrm{db}$-cAMP, and the protein levels of Oct-6/ SCIP were quantified as a marker for differentiation. Elevation of cAMP increased the basal level of Oct-6/SCIP expression, and this was further enhanced by overexpression of the $\mathrm{p} 65$ subunit of NF- $\kappa$ B. Notably, db-cAMP did not increase Oct-6/SCIP protein when the cells expressed the S276A mutant p65. Furthermore, a phospho-mimetic mutant p65 S276D itself upregulated Oct-6/ SCIP expression similar to the level induced by db-cAMP treatment of the control cells. Treating the p65 S276D-expressing cells with db-cAMP did not further increase the Oct-6/SCIP expression (Fig. $3 A, B$ ). We confirmed that the expression level of wildtype p65, p65 S276A, and S276D, when transfected into Schwann cells, was similar (supplemental Fig. 1, available at www.jneurosci.org as supplemental material). Finally, the response to dbcAMP treatment was abrogated by expression of the nondegradable $\mathrm{I} \kappa \mathrm{B}$ mutant, which prevents NF- $\kappa \mathrm{B}$ activation (Fig. $3 A, B$ ).

To determine whether NF- $\kappa \mathrm{B}$ activation also affects the mRNA levels of Oct-6/SCIP, total RNA was isolated from cells expressing wild-type p65, the p65 S276A, or S276D mutants, or the $\mathrm{I} \kappa \mathrm{B}$ mutant, and expression of Oct-6/SCIP transcript was evaluated by quantitative PCR. As expected, elevation of cAMP
A

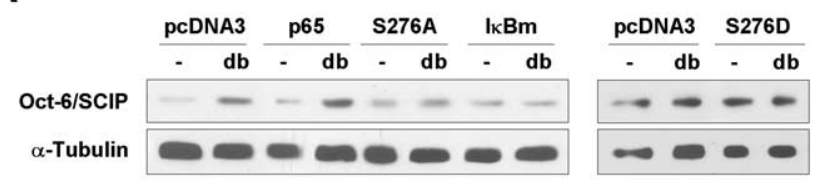

B

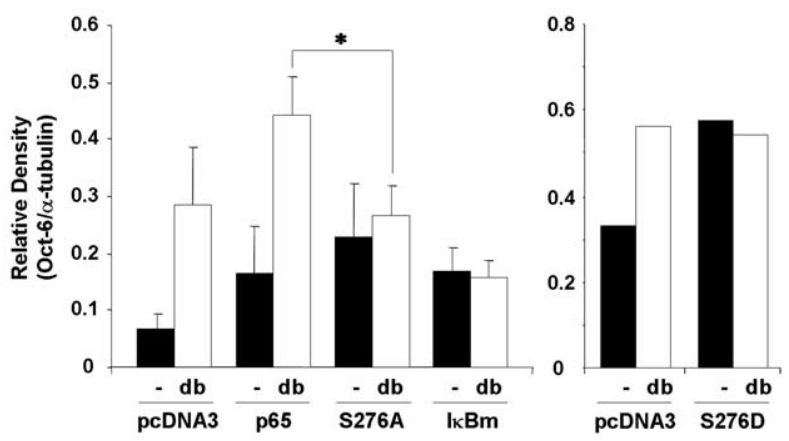

C

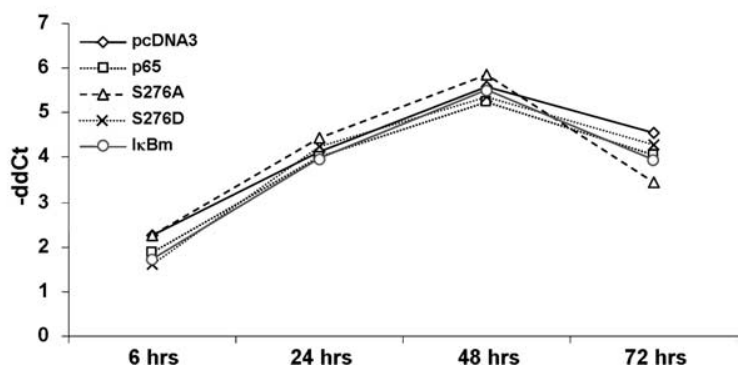

Figure 3. The S276A mutant of 065 prevents cAMP-mediated 0ct-6/SCIP protein upregulation without affecting its $m R N A$ levels. $A$, Schwann cells were transfected with control vector or a plasmid expressing p65 wild-type, S276A, or S276D mutant p65 or I $\mathrm{KBm}$. Twenty-four hours later, the cells were treated with db-CAMP $(500 \mu \mathrm{M})$ for an additional $24 \mathrm{~h}$ and harvested for immunoblotting with an antibody against $0 \mathrm{ct}-6 / \mathrm{SCIP}$. $\alpha$-Tubulin was used as a loading control. $B$, Quantitative analysis of the amount of $0 \mathrm{ct}-6 / \mathrm{SCIP}$ normalized to $\alpha$-tubulin. Data represent mean \pm SEM (left; $n=4 ;{ }^{*} p=0.042$, based on a Student's $t$ test; right, $n=2$ ). C, Schwann cells were transfected with the indicated plasmids, and total RNA was isolated at different times after treatment of db-cAMP: 6, 24, 48, and $72 \mathrm{~h}$. After reverse transcription of total RNA, the level of $0 \mathrm{ct}-6 / \mathrm{SCIP}$ transcript was compared with that of Pgk1 as a normalizer by quantitative $P C R$. Each PCR reaction was triplicated.

dramatically upregulated the basal level of Oct-6/SCIP mRNA even at $6 \mathrm{~h}$ exposure to db-cAMP ( $\sim 200 \%$ over no treatment); it continued to increase up to $48 \mathrm{~h}$ and dropped off by $72 \mathrm{~h}$, which is consistent with previous findings (Monuki et al., 1989). Interestingly, however, none of the ectopically expressed p65 constructs or the $\mathrm{I} \kappa \mathrm{B}$ mutant altered the level or kinetics of Oct- $6 /$ SCIP mRNA induction (Fig. $3 C$ ). This result contrasts with the effect of NF- $\kappa \mathrm{B}$ on the protein, suggesting that there are different regulatory mechanisms controlling Oct-6/SCIP protein and message and that the differentiation of Schwann cells by increasing cAMP requires activation of NF- $\kappa \mathrm{B}$ through S276 phosphorylation, which regulates the protein level of Oct-6/SCIP.

PKA activation and p65 phosphorylation parallel myelination of the sciatic nerve in vivo

Increasing cAMP levels in Schwann cells is known to mimic axonal contact (Ratner et al., 1984; Mirsky et al., 1990; Morgan et al., 1991), and the downstream effector of this second messenger, PKA, has been shown to be essential for myelin formation in vitro (Howe and McCarthy, 2000). Surprisingly, however, the activation of PKA during myelination in vivo has not been directly 


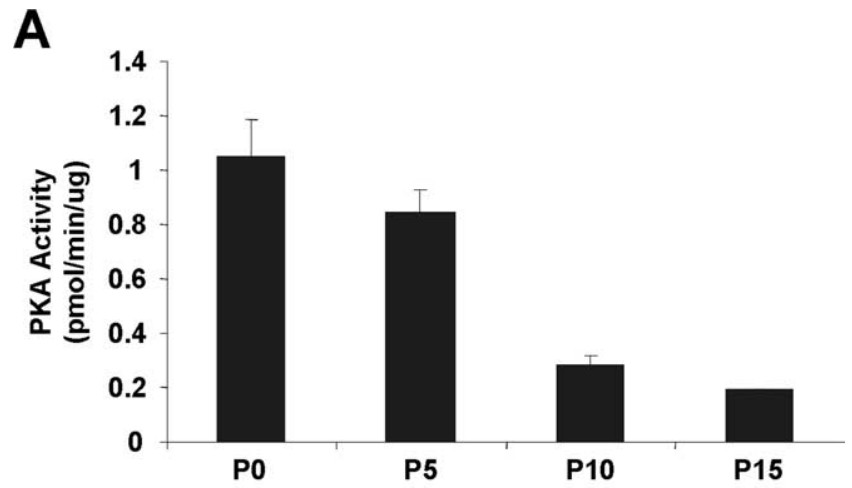

B

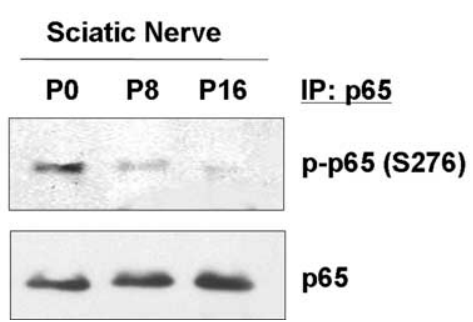

Figure 4. The kinetics of PKA activity correlate with those of p65 phosphorylation during myelination in vivo. $A$, PKA activity was measured in lysates from rat sciatic nerves collected at the indicated postnatal days. ( $n=3$; the mean \pm SEM is depicted). $\boldsymbol{B}$, Sciatic nerve lysates collected from rats at the indicated postnatal days were subjected to immunoprecipitation (IP) with a 65 antibody, and the precipitates were Western blotted for phospho-\$276 p65 and total p65. P, Postnatal day.

evaluated. We hypothesized that PKA would be activated during the period of myelination in the developing sciatic nerve. In addition, given the results above, we predicted that the $\mathrm{p} 65$ subunit of NF- $\kappa \mathrm{B}$ would be phosphorylated in parallel to PKA activation. To test our hypotheses, rat sciatic nerves were isolated at several stages during the first 2 weeks of postnatal development, the period of myelin formation in rats (Webster, 1971), and the activity of PKA, and the phosphorylation status of p65 at S276 were measured. PKA activity was highest in the nerves on the day of birth and diminished over the next 2 weeks (Fig. 4A). Similarly, phospho-p65 was detected on day 0 but by postnatal day 16 was undetectable (Fig. 4B). Interestingly, although we cannot rule out some contribution of the PKA activity from the axons, these kinetics mirror those reported previously for NF- $\kappa$ B activation in Schwann cells during myelination in rat sciatic nerves (Nickols et al., 2003).

\section{The p65 subunit of NF- $\kappa$ B is phosphorylated by PKA during myelination in vitro}

To further investigate whether PKA activates NF- $\kappa \mathrm{B}$ by phosphorylating the p65 subunit during myelination, we used an in vitro model in which sensory neurons from DRG were cocultured with Schwann cells under conditions that allow for myelination (Einheber et al., 1993). First, PKA activity was examined at several time points to determine whether it was activated during myelination. After the initiation of myelin formation by addition of ascorbic acid, PKA activity slowly increased, reaching a peak level at approximately day 6 and then decreasing back to basal levels by day 12. As expected, addition of the PKA inhibitor H89 on day 6 dramatically attenuated the level of activation (Fig. $5 A$ ). We then assessed the phosphorylation status of p65 during myelination in these cocultures and found that it paralleled PKA activation, peaking near day 6 and then dropping off by day 12 . This endog-
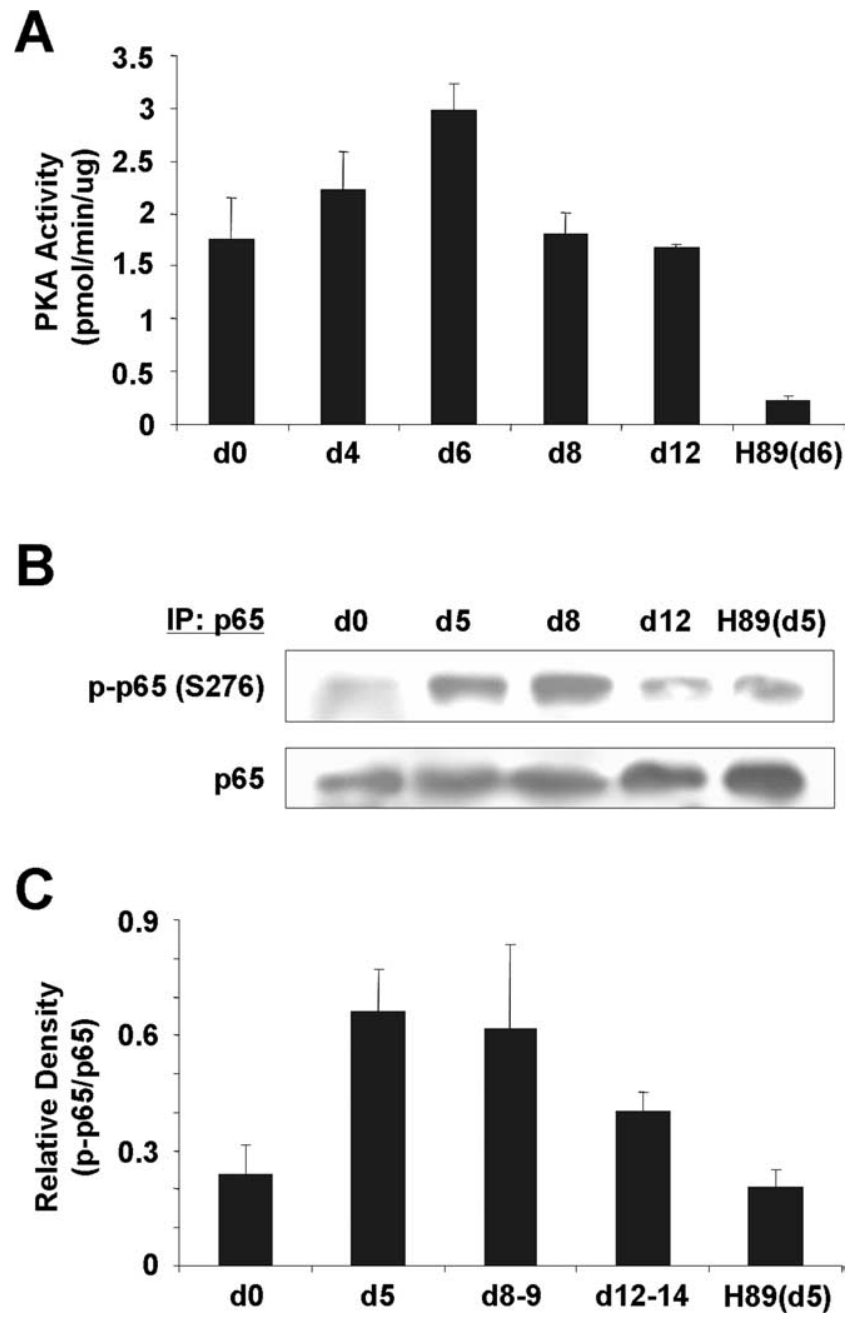

Figure 5. Inhibition of PKA attenuates phosphorylation of the $\mathrm{p} 65$ subunit during myelination in vitro. $\boldsymbol{A}$, PKA activity was measured in lysates from rat DRG-Schwann cell cocultures harvested at the indicated days after induction of myelination. Some cocultures were treated with $\mathrm{H} 89(10 \mu \mathrm{m})$ on day 4 and harvested on day 6. $\boldsymbol{B}, \mathrm{DRG}-\mathrm{Sch}$ wann cell cocultures were harvested at the indicated days, and the lysates were subjected to immunoprecipitation (IP) with a 165 antibody. The precipitates were then Western blotted for phospho-\$276 p65 and total p65. Some cocultures were treated with $\mathrm{H} 89(10 \mu \mathrm{m})$ on day 3 and harvested on day 5 . The image is representative of three separate experiments. C, Quantitative analysis of the amount of phospho-p65 normalized to the total amount of p65. Data represent mean \pm SEM.

enous phosphorylation of p65 was PKA dependent, because addition of $\mathrm{H} 89$ substantially reduced the amount of phospho-p65 (Fig. $5 B, C$ ).

Blocking PKA activity reduces NF- $\kappa \mathrm{B}$ transcriptional activity but not its DNA binding in myelinating cocultures

We observed that increasing cAMP levels or activating PKA in cultures of pure Schwann cells enhanced the transcriptional activity of NF- $\kappa$ B but did not substantially enhance its binding to DNA (Fig. 2). Therefore, we wanted to determine whether or not the increase in NF- $\kappa \mathrm{B}$ binding or transcriptional activity seen during myelin formation was dependent on PKA. In agreement with our previous findings (Nickols et al., 2003), the amount of $\mathrm{NF}-\kappa \mathrm{B}$ capable of binding DNA increased after the induction of myelin formation; however, addition of H89 to the cells $24 \mathrm{~h}$ before harvesting had no effect, suggesting that activation of NF- $\kappa \mathrm{B}$ binding was not dependent on PKA (Fig. 6A). To assess the effect of PKA on the transcriptional activity of NF- $\kappa$, we 


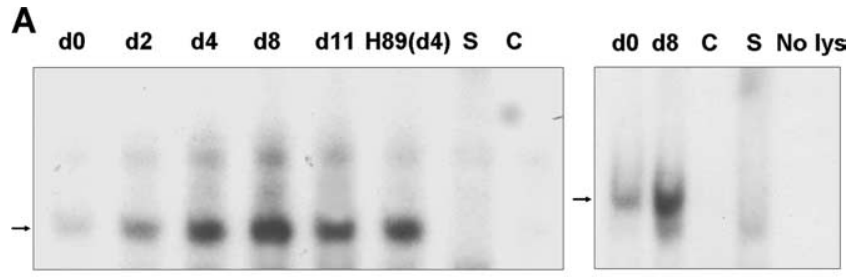

B

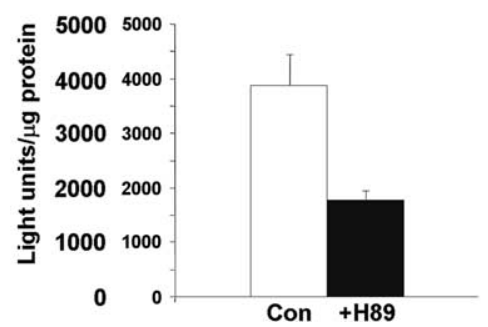

Figure 6. Blocking PKA activity reduces transcriptional activity of NF- $\kappa$ B but not its DNA binding. $A$, EMSA analysis of lysates from rat DRG-Schwann cell cocultures collected on the indicated days was used to evaluate DNA binding of NF- $\kappa$ B. Some cocultures were treated with $\mathrm{H} 89(10 \mu \mathrm{M})$ on day 2 and harvested on day 4. The band corresponding to NF- $\kappa$ B binding (arrowhead) was confirmed by super shift using an antibody to p65 (S) and by adding excess unlabeled oligonucleotide (C). No binding was detected if the $\mathrm{p} 65$ antibody was incubated only with the labeled oligonucleotide in the absence of lysates (right). $\boldsymbol{B}, \mathrm{DRG}-\mathrm{Sch}$ wann cell cocultures were prepared from transgenic mice carrying an NF- $\kappa B$-luciferase reporter gene, and the cells were treated with $\mathrm{H} 89(10 \mu \mathrm{m})$ or untreated for $2 \mathrm{~d}$ after inducing myelination and were then harvested for luciferase assay. The luciferase activity was normalized to the amount of protein. Data represent mean $\pm \operatorname{SEM}(n=3)$.

used transgenic mice expressing an NF- $\kappa \mathrm{B}$ reporter construct (Blackwell et al., 2000). DRG-Schwann cell cocultures were prepared from these mice, and the endogenous luciferase activity was measured after initiating myelination with and without the addition of $\mathrm{H} 89$ for $24 \mathrm{~h}$ before harvesting. Unlike DNA binding, the PKA inhibitor reduced the transcriptional activity of NF- $\kappa$ B by $50 \%$ (Fig. $6 \mathrm{~B}$ ), thereby indicating that DNA binding and activation of transcription by NF- $\kappa \mathrm{B}$ is differentially regulated in myelinating Schwann cells, with PKA stimulating that the latter.

\section{Phosphorylation of p65 at serine 276 is required for myelin formation}

To determine functional relevance of $\mathrm{p} 65$ phosphorylation during myelin formation, we used the S276A mutant of p65, which blocked the stimulation of NF- $\kappa \mathrm{B}$-dependent transcription in response to increased cAMP (Fig. $2 A$ ). Cultured Schwann cells were transfected, using the nucleofector electroporation system, with expression constructs for wild-type p65, the S276A or the S276D mutants of p65, or a vector control and then were seeded onto DRG neurons. As a negative control, Schwann cells were also transfected with the NF- $\kappa \mathrm{B}$ inhibitor $\mathrm{I} \kappa \mathrm{B}$, mutated at the serine sites required for its degradation. After allowing myelination to proceed for 9-10 d, the amount of myelination was quantified by counting the number of segments that were immunopositive for MBP. As shown in Figure 7, expression of p65 or the phospho-mimetic mutant p65 S276D slightly increased the number of MBP-positive segments; however, S276A p65 significantly suppressed myelin formation. As shown previously (Nickols et al., 2003), the I $\kappa \mathrm{B}$ mutant reduced the amount of myelin produced. In addition, when the cultures were treated with the PKA inhibitors H89 or KT5720 throughout the myelinating period, there was a dramatic reduction in myelination. These results re- veal a requirement for PKA-mediated phosphorylation of the p65 subunit of NF- $\kappa$ B in Schwann cell differentiation into a myelinating phenotype induced by neuronal contact.

\section{Discussion}

It has been known for $>20$ years that elevation of intracellular cAMP in Schwann cells acts as an instructive signal for their differentiation into a myelinating phenotype (Sobue and Pleasure, 1984; Sobue et al., 1986). However, the mechanisms by which this signal is transduced remained essentially unknown. Recently, we demonstrated a requirement for NF- $\kappa \mathrm{B}$ activation in the formation of myelin by Schwann cells (Nickols et al., 2003). Inhibition of NF- $\kappa \mathrm{B}$ signaling or genetic deletion of the p65 subunit in Schwann cells significantly attenuated myelination in DRG-Schwann cell cocultures. How this transcription factor was activated during myelination had not been determined.

Based on the finding from Sankar Ghosh's group that cAMPdependent PKA could phosphorylate and thereby activate the p65 subunit of NF- $\kappa$ B (Zhong et al., 1997), we hypothesized that increases in cAMP in Schwann cells activates PKA, which then phosphorylates and stimulates NF- $\kappa \mathrm{B}$, resulting in Schwann cell differentiation. Here, we demonstrate that elevation of cAMP induced phosphorylation of the $\mathrm{p} 65$ subunit of NF- $\kappa$ B by PKA in Schwann cells, and this increased its transcriptional activity. The activation of PKA and phosphorylation of $\mathrm{p} 65$ were also detected in myelinating cocultures and in sciatic nerves during the period of myelin formation. Preventing this NF- $\kappa$ B phosphorylation by addition of PKA inhibitors or expression of an S276A mutant p65 blocked the differentiation of Schwann cells induced by increasing cAMP or by coculturing them with sensory neurons. These findings suggest that PKA-mediated activation of NF- $\kappa \mathrm{B}$ is required for peripheral myelin formation.

The effect of cAMP on cultured Schwann cells is complex and not well understood. Although originally shown to promote proliferation (Raff et al., 1978a,b), increasing the cyclic nucleotide has also been shown to induce Schwann cell differentiation. In the initial reports of cAMP-mediated differentiation, neonatal rat Schwann cells were treated with high concentrations of cAMP analogs $(0.5-3 \mathrm{mM})$ or forskolin $(100-250 \mu \mathrm{M})$, and this upregulated the expression of surface galactocerebroside $\mathrm{C}$, a lipid originally thought to be reflective of myelinating Schwann cells (Sobue and Pleasure, 1984) but later also shown to be expressed by nonmyelinating Schwann cells in adult nerves (Jessen et al., 1985). Since then, numerous reports have demonstrated either a proliferation response or a differentiation response to cAMP, for example, by demonstrating an increase in the expression of $\mathrm{P} 0$ (Lemke and Chao, 1988; Morgan et al., 1991), the O4 antigen (Mirsky et al., 1990; Morgan et al., 1991), the myelin promoting transcription factor Oct-6/SCIP (Monuki et al., 1989), and other myelin-related genes. The divergent response to cAMP has been suggested to depend on the levels of cAMP, differentiation requiring a higher concentration of cAMP (Yamada et al., 1995), whereas just a slight increase in the nucleotide is associated with proliferation and cyclin D1 induction (Iacovelli et al., 2007). However, even at relatively low doses of forskolin (1-10 $\mu \mathrm{M})$, an increase in P0 (Monuki et al., 1989) and MBP mRNA was detected (Lemke and Chao, 1988). More recently, these disparate effects of cAMP have been attributed to the presence of growth factors and/or serum. Increasing cAMP alone, in the absence of serum or exogenous growth factors, does not increase proliferation but induces markers of differentiation, e.g., P0 (Morgan et al., 1991). However, when cAMP is elevated in concert with exposure to serum or growth factors, such as neuregulin, then a 
synergistic effect is seen and there is robust cell proliferation (Lemke and Brockes, 1984; Stewart et al., 1991; Kim et al., 1997; Rahmatullah et al., 1998; Monje et al., 2006).

In the experiments presented here, rat Schwann cells were maintained in $2 \mu \mathrm{M}$ forskolin in serum-containing media to promote proliferation. However, based on the aforementioned studies, the Schwann cells were transferred into serum-free, defined media without forskolin to assess differentiation and NF- $\kappa \mathrm{B}$ signaling. Under these conditions, we observed that high levels of cAMP reliably resulted in p65 phosphorylation (Fig. 1), transcription activation (Fig. 2), and Oct-6/SCIP induction (Fig. 3). We have not investigated whether NF- $\kappa \mathrm{B}$ has a role in the proliferative response of cAMP when coupled with various growth factors or serum; however, in our previous study with cocultures of Schwann cells and sensory neurons, we did not observe any change in Schwann cell proliferation when NF- $\kappa \mathrm{B}$ was inhibited or p65 genetically deleted, although myelination was blocked (Nickols et al., 2003). These results suggest that NF- $\kappa \mathrm{B}$ is primarily associated with a differentiation response. Nevertheless, this transcription factor has been shown to promote cell proliferation in other systems (Courtois and Gilmore, 2006; De Bosscher et al., 2006; Perkins and Gilmore, 2006; Van Waes, 2007); therefore, we cannot rule out a potential role for NF- $\kappa \mathrm{B}$ in the proliferation of Schwann cells under specific conditions or developmental states in vivo.

As a marker for Schwann cell differentiation, we quantified the induction of Oct-6/SCIP, a transcription factor initially identified based on its induction after cAMP treatment of Schwann cells (Monuki et al., 1989) and known to be required for normal myelination. Genetic deletion of Oct-6/SCIP in mice delays the formation of peripheral myelin, and the animals exhibit sporadic fibers with disorganized myelin (Bermingham et al., 1996; Jaegle et al., 1996; Ghazvini et al., 2002). Although Oct-6/SCIP was identified by Monuki et al. (1989), the mechanism by which cAMP mediates this effect has, surprisingly, remained unknown. We found that blocking NF- $\kappa \mathrm{B}$ with the I $\kappa \mathrm{B}$ mutant or preventing PKA-mediated phosphorylation by expressing the S276A mutant $\mathrm{p} 65$ subunit abrogated Oct6/SCIP protein induction by cAMP (Fig. 3). This corroborates our previous observation that inhibition of NF- $\kappa$ B in DRGSchwann cell cocultures attenuated the DNA binding activity of Oct-6/SCIP (Nickols et al., 2003). Together, these results indicate that NF- $\kappa \mathrm{B}$ is an upstream activator of Oct-6/SCIP but requires PKA-mediated phosphorylation to induce its expression, because ectopic expression of p65 alone was not sufficient to increase Oct-6/SCIP levels, and the phospho-mimetic p65 mutant S276D by itself did (Fig. 3).

Surprisingly, altering NF- $\kappa$ B signaling by overexpressing p 65 , mutants thereof, or a mutant $\mathrm{I} \kappa \mathrm{B}$ did not affect the mRNA levels of Oct-6/SCIP. These findings indicate the existence of differential mechanisms for controlling Oct-6/SCIP protein and its mRNA. It is possible that NF- $\kappa \mathrm{B}$ activation causes posttranslational modifications of Oct-6/SCIP or the expression of an associated protein that changes the stability of the Oct-6/SCIP protein. The ability of NF- $\kappa \mathrm{B}$ to regulate the protein expression of Oct-6/SCIP is the first mechanistic connection between cAMP elevation and induction of this myelin promoting POU-domain transcription factor and the first demonstration of differential regulation of Oct-6/SCIP protein and message. How NF- $\kappa$ B controls Oct-6/SCIP protein levels is an interesting topic for future studies.

Our results demonstrate that PKA is activated during myelination in vivo (Fig. 4) and that cAMP-induced differentiation of Schwann cells requires PKA-mediated NF- $\kappa$ B activation (Figs. 3, 7). However, axonal signals may activate PKA through a mechanism independent of cAMP. Zhong et al. were the first to report that PKA could transactivate NF- $\kappa \mathrm{B}$, but they reported that the phosphorylation was not dependent on cAMP (Zhong et al., 1997). Their data suggested a complex of NF- $\kappa \mathrm{B}-\mathrm{I} \kappa \mathrm{B}$ and the catalytic subunit of PKA, which phosphorylates $\mathrm{p} 65$ after release 
of $\mathrm{I} \kappa \mathrm{B}$, without any requirement for cAMP. They further proposed that there are two separate pools of PKA, one complexed with $I \kappa \mathrm{B}$ and one bound to the regulatory subunit of PKA, which binds cAMP. Hence, PKA activation would not increase DNA binding of NF- $\kappa \mathrm{B}$, because it could not liberate the transcription factor from $\mathrm{I} \kappa \mathrm{B}$ but only increase its ability to activate transcription. Indeed, they did not detect PKA regulating DNA binding, but it did enhance transcription activity through phosphorylation, which recruited the coactivator CBP/P300 (Zhong et al., 1998). Here, we also did not detect any significant effect of PKA on NF- $\kappa$ B binding (Fig. $2 B$ ), although it did increase transcription (Fig. $2 A$ ), meaning that there was no additional release of NF- $\kappa$ B from $\mathrm{I} \kappa \mathrm{B}$. However, unlike Zhong et al. (1997), we did see cAMP induced PKA phosphorylation of p65 and an increase in transcription in response to elevated cAMP (Fig. 2). These results suggest that, in Schwann cells, there is a basal level of active NF- $\kappa \mathrm{B}$ binding to DNA and that it can be further activated to promote transcription through cAMP-activated PKA.

The inability of cAMP to increase DNA binding of NF- $\kappa \mathrm{B}$ suggests that there are additional axonally derived signals that stimulate the NF- $\kappa \mathrm{B}$ pathway, because we observed an increase in NF- $\kappa \mathrm{B}$ binding during myelination (Fig. 6). However, it is also possible that only one signal from an axon activates both PKA and NF- $\kappa \mathrm{B}$ in vivo. Increasing cAMP in cultured Schwann cells may only mimic part of the axonal signal. One particularly interesting candidate is membranebound neuregulin 1 (Nrg1) type III. Recent studies have revealed that this isoform of $\mathrm{Nrg} 1$ regulates myelin thickness to match axon caliber, and it also instructs Schwann cells to ensheath axons (Michailov et al., 2004; Taveggia et al., 2005). Furthermore, Leimeroth et al. demonstrated that Nrg1 type III induced Oct-6/SCIP in Schwann cell precursors (Leimeroth et al., 2002). It will be interesting to determine in future studies whether axonal Nrg1 type III activates PKA or NF- $\kappa \mathrm{B}$ in Schwann cells or whether another axonal signal exists.

\section{References}

Bermingham Jr JR, Scherer SS, O’Connell S, Arroyo E, Kalla KA, Powell FL, Rosenfeld MG (1996) Tst-1/Oct-6/SCIP regulates a unique step in peripheral myelination and is required for normal respiration. Genes Dev 10:1751-1762.

Blackwell TS, Yull FE, Chen CL, Venkatakrishnan A, Blackwell TR, Hicks DJ, Lancaster LH, Christman JW, Kerr LD (2000) Multiorgan nuclear factor kappa B activation in a transgenic mouse model of systemic inflammation. Am J Respir Crit Care Med 162:1095-1101.

Campbell KJ, Perkins ND (2004a) Post-translational modification of Re1A(p65) NF-kappaB. Biochem Soc Trans 32:1087-1089.

Campbell KJ, Perkins ND (2004b) Reprogramming RelA. Cell Cycle 3:869-872.

Chen CL, Yull FE, Kerr LD (1999) Differential serine phosphorylation regulates IkappaB-alpha inactivation. Biochem Biophys Res Commun 257:798-806.

Courtois G, Gilmore TD (2006) Mutations in the NF-kappaB signaling pathway: implications for human disease. Oncogene 25:6831-6843.

De Bosscher K, Vanden Berghe W, Haegeman G (2006) Cross-talk between nuclear receptors and nuclear factor kappaB. Oncogene 25:6868-6886.

Einheber S, Milner TA, Giancotti F, Salzer JL (1993) Axonal regulation of Schwann cell integrin expression suggests a role for alpha 6 beta 4 in myelination. J Cell Biol 123:1223-1236.

Gentry JJ, Casaccia-Bonnefil P, Carter BD (2000) Nerve growth factor activation of nuclear factor kappaB through its p75 receptor is an anti-apoptotic signal in RN22 schwannoma cells. J Biol Chem 275:7558-7565.

Ghazvini M, Mandemakers W, Jaegle M, Piirsoo M, Driegen S, Koutsourakis M, Smit X, Grosveld F, Meijer D (2002) A cell type-specific allele of the
POU gene Oct-6 reveals Schwann cell autonomous function in nerve development and regeneration. EMBO J 21:4612-4620.

Hoffmann A, Natoli G, Ghosh G (2006) Transcriptional regulation via the NF-kappaB signaling module. Oncogene 25:6706-6716.

Howe DG, McCarthy KD (2000) Retroviral inhibition of cAMP-dependent protein kinase inhibits myelination but not Schwann cell mitosis stimulated by interaction with neurons. J Neurosci 20:3513-3521.

Huber LJ, Chao MV (1995) A potential interaction of p75 and trkA NGF receptors revealed by affinity crosslinking and immunoprecipitation. J Neurosci Res 40:557-563.

Iacovelli J, Lopera J, Bott M, Baldwin E, Khaled A, Uddin N, Fernandez-Valle C (2007) Serum and forskolin cooperate to promote G1 progression in Schwann cells by differentially $\mathrm{r}$ regulating cyclin D1, cyclin E1, and p27(Kip) expression. Glia 55:1638-1647.

Jaegle M, Mandemakers W, Broos L, Zwart R, Karis A, Visser P, Grosveld F, Meijer D (1996) The POU factor Oct-6 and Schwann cell differentiation. Science 273:507-510.

Jessen KR, Morgan L, Brammer M, Mirsky R (1985) Galactocerebroside is expressed by non- myelin-forming Schwann cells in situ. J Cell Biol 101:1135-1143.

Kim HA, DeClue JE, Ratner N (1997) cAMP-dependent protein kinase A is required for Schwann cell growth: interactions between the cAMP and neuregulin/tyrosine kinase pathways. J Neurosci Res 49:236-247.

Kurrasch DM, Huang J, Wilkie TM, Repa JJ (2004) Quantitative real-time polymerase chain reaction measurement of regulators of G-protein signaling mRNA levels in mouse tissues. Methods Enzymol 389:3-15.

Leimeroth R, Lobsiger C, Lussi A, Taylor V, Suter U, Sommer L (2002) Membrane-bound neuregulin1 type III actively promotes Schwann cell differentiation of multipotent Progenitor cells. Dev Biol 246:245-258.

Lemke G, Chao M (1988) Axons regulate Schwann cell expression of the major myelin and NGF receptor genes. Development 102:499-504.

Lemke GE, Brockes JP (1984) Identification and purification of glial growth factor. J Neurosci 4:75-83.

Michailov GV, Sereda MW, Brinkmann BG, Fischer TM, Haug B, Birchmeier C, Role L, Lai C, Schwab MH, Nave KA (2004) Axonal neuregulin-1 regulates myelin sheath thickness. Science 304:700-703.

Mirsky R, Dubois C, Morgan L, Jessen KR (1990) 04 and A007-sulfatide antibodies bind to embryonic Schwann cells prior to the appearance of galactocerebroside; regulation of the antigen by axon-Schwann cell signals and cyclic AMP. Development 109:105-116.

Monje PV, Bartlett Bunge M, Wood PM (2006) Cyclic AMP synergistically enhances neuregulin-dependent ERK and Akt activation and cell cycle progression in Schwann cells. Glia 53:649-659.

Monuki ES, Weinmaster G, Kuhn R, Lemke G (1989) SCIP: a glial POU domain gene regulated by cyclic AMP. Neuron 3:783-793.

Morgan L, Jessen KR, Mirsky R (1991) The effects of cAMP on differentiation of cultured Schwann cells: progression from an early phenotype $(04+)$ to a myelin phenotype $(\mathrm{P} 0+$, GFAP-, N-CAM-, NGFreceptor-) depends on growth inhibition. J Cell Biol 112:457-467.

Nickols JC, Valentine W, Kanwal S, Carter BD (2003) Activation of the transcription factor NF- kappaB in Schwann cells is required for peripheral myelin formation. Nat Neurosci 6:161-167.

Perkins ND, Gilmore TD (2006) Good cop, bad cop: the different faces of NF-kappaB. Cell Death Differ 13:759-772.

Raff MC, Hornby-Smith A, Brockes JP (1978a) Cyclic AMP as a mitogenic signal for cultured rat Schwann cells. Nature 273:672-673.

Raff MC, Abney E, Brockes JP, Hornby-Smith A (1978b) Schwann cell growth factors. Cell 15:813-822.

Rahmatullah M, Schroering A, Rothblum K, Stahl RC, Urban B, Carey DJ (1998) Synergistic regulation of Schwann cell proliferation by heregulin and forskolin. Mol Cell Biol 18:6245-6252.

Ratner N, Glaser L, Bunge RP (1984) PC12 cells as a source of neuritederived cell surface mitogen, which stimulates Schwann cell division. J Cell Biol 98:1150-1155.

Shuman S, Hardy M, Sobue G, Pleasure D (1988) A cyclic AMP analogue induces synthesis of a myelin-specific glycoprotein by cultured Schwann cells. J Neurochem 50:190-194.

Sobue G, Pleasure D (1984) Schwann cell galactocerebroside induced by derivatives of adenosine $3^{\prime}, 5^{\prime}$-monophosphate. Science 224:72-74.

Sobue G, Shuman S, Pleasure D (1986) Schwann cell responses to cyclic AMP: proliferation, change in shape, and appearance of surface galactocerebroside. Brain Res 362:23-32. 
Stewart HJ, Eccleston PA, Jessen KR, Mirsky R (1991) Interaction between cAMP elevation, identified growth factors, and serum components in regulating Schwann cell growth. J Neurosci Res 30:346-352.

Sun Z, Andersson R (2002) NF-kappaB activation and inhibition: a review. Shock 18:99-106.

Taveggia C, Zanazzi G, Petrylak A, Yano H, Rosenbluth J, Einheber S, Xu X, Esper RM, Loeb JA, Shrager P, Chao MV, Falls DL, Role L, Salzer JL (2005) Neuregulin-1 type III determines the ensheathment fate of axons. Neuron 47:681-694.

Van Waes C (2007) Nuclear factor-kappaB in development, prevention, and therapy of cancer. Clin Cancer Res 13:1076-1082.

Webster HD (1971) The geometry of peripheral myelin sheaths during their formation and growth in rat sciatic nerves. J Cell Biol 48:348-367.
Yamada H, Komiyama A, Suzuki K (1995) Schwann cell responses to forskolin and cyclic AMP analogues: comparative study of mouse and rat Schwann cells. Brain Res 681:97-104.

Zhong H, SuYang H, Erdjument-Bromage H, Tempst P, Ghosh S (1997) The transcriptional activity of NF-kappaB is regulated by the IkappaBassociated PKAc subunit through a cyclic AMP-independent mechanism. Cell 89:413-424.

Zhong H, Voll RE, Ghosh S (1998) Phosphorylation of NF-kappa B p65 by PKA stimulates transcriptional activity by promoting a novel bivalent interaction with the coactivator CBP/p300. Mol Cell 1:661-671.

Zorick TS, Syroid DE, Arroyo E, Scherer SS, Lemke G (1996) The transcription factors SCIP and Krox-20 mark distinct stages and cell fates in Schwann cell differentiation. Mol Cell Neurosci 8:129-145. 